\title{
Exploration on College Students' Learning Behavior and Career Choice Behavior under Micro-culture Background
}

\author{
Li Wang * \\ Tianjin Agricultural University \\ Tianjin, China 300384 \\ Yingying Wang \\ Tianjin Agricultural University \\ Tianjin, China 300384
}

\author{
Qin Zou \\ Tianjin Agricultural University \\ Tianjin, China 300384 \\ Tingfang $\mathrm{Wu}$ \\ Tianjin Agricultural University \\ Tianjin, China 300384
}

\begin{abstract}
As a double-edged sword, micro-culture has deeply influenced college students' life on campus at present. This paper researches college students' learning behavior and career choice behavior under micro-culture background so as to provide references for schools in quality improvement of teaching as well as talent training.
\end{abstract}

Keywords-micro-culture; learning behavior; career choice behavior

\section{INTRODUCTION}

We are in the age full of computer, internet, mobile communication network and personal mobile devices (tablet $\mathrm{PC}$ and smart phone, etc.). With many micro features (WeChat, Weibo, micro film, QQ on mobile phone and micro public welfare, etc.), it is the "micro-age" inevitably accompanying by new "micro-culture". In narrow sense, "micro-culture" refers to the spirit phenomenon of values and behavior pattern gradually formed after entering the personal internet age, developing rapidly with the development of science and technology, paying attention to individual and microcosmic things and focusing on subjectivity and equality. ${ }^{[1]}$

Micro-culture is a young and lively culture encouraging people to extend individuality and DIY ${ }^{[2]}$. Naturally, college students become the main part of it. However, micro-culture advocates freedom, owning more game spirit and less practicability. Involved in consumerism passively, college students in micro-age are easy to be infatuated with gadgets ${ }^{[3]}$ in private life, losing heavy responsibility, lofty ideal, broad vision and broad mind. Therefore, it is of vital importance to analyze micro-culture and guide college students' learning behavior and career choice behavior in adopting good points and avoiding shortcomings.

The research group has made in-depth analysis in the

Fund project: College students' training program on innovation and entrepreneurship in universities of Tianjin "Exploration on Influence of Micro-culture on College Students' Learning Behavior and Career Choice Behavior" (201510061115)

*Corresponding author: Li Wang, research assistant, research direction: higher education management. Qin Zou, undergraduate in school of basic science of Tianjin Agricultural University influence of micro-culture on college students' learning behavior and career choice behavior through questionnaire survey.

\section{INFLUENCE OF MICRO-CULTURE ON COLLEGE STUDENTS' LEARNING BEHAVIOR}

\section{A. Micro-culture Has Brought New Learning Style}

According to the investigation, $93.8 \%$ of college students address network mobile devices are conducive to learning; $60.8 \%$ of them turn to the network in face of learning problems; $18.4 \%$ of them often exchange ideas with teachers and classmates in learning problems through network mobile devices. It shows college students are gradually adapting to new learning style under micro-culture background, but problems exist when they use network mobile devices to better realize learning exchange.

\section{B. Micro-culture Has Promoted Fragmented Micro-learning Development}

Under micro-culture background, new-type mobile fragmented micro-learning style is developing step by step. The investigation finds most students agree to learn in spare time, but various reasons like personal sluggishness and others affairs make actual learning behavior not in accordance with thought. College students accept the combination of learning in fragmented time and classroom, but having not roundly and deeply realized the advantages (improve learning efficiency and increase learning opportunities) of learning through making use of fragmented time. The investigation proves both teachers and students support micro-learning. In consequence, schools should give more preferential policies and encourage teachers with strength to spare to develop excellent microlearning resources and PPT documents and video data, realizing real-time update with the help of WeChat. ${ }^{[4-5]}$ When developing micro-learning resources, teachers should pay attention to the standardization of text and images on learning 
materials and strengthening interestingness, so as to arouse students' learning interest and enthusiasm.

\section{Micro-culture Helps to Publicize in Learning and Education}

People can freely express their wills and demands through micro-culture as an information channel. Micro-culture has folk grassroots nature. To a certain extent and scope, the information release and spread of it will form public opinions and have social mobilization function. Social pressure will generate through the dispersive social energy gathered by wide spread of information. It helps college students to express their wills and demands, and the formation of public opinion influence, of which schools can take advantage to carry out construction of study style and publicize deeds of excellent student representatives.

\section{Micro-culture Causes Decline of Learning Interest Easily}

We have surveyed contents cared by college students on the internet. Results show the top three are: politics of current events, people's livelihood, entertainment stars and TV play, film as well as variety show, not including learning contents, in accordance with the subjectivity and entertainment of micro-culture.

$91.8 \%$ of college students deny the "idea of uselessness of learning" on network. Meanwhile, $77.6 \%$ of them address they don't want to learn every now and then, because the lessons taught by teachers are too boring, learning contents are too difficult and recreational activities occupy too much time. The disciplinary knowledge in university is systematic and profound without interestingness. Moreover, students have weak basis and learning ability and think learning contents are too difficult. Teachers should spend more time in improving the artistry of classroom to arouse students' learning initiative by using network mobile tools. As mentioned above, recreational activities occupy too much time so that students dislike learning, showing the contradiction between young people's lively personality without restraints and diversified, open and recreational micro-age.

\section{E. Micro-culture Results in the Flooding of Fragmented Thinking}

On the whole, micro-culture tends to be fragmented and plane and like fast food and bubble, triggering information flooding in society and knowledge accumulation decline, influencing knowledge system integration and then restricting overall field of view. The investigation finds $70 \%$ of college students think fragmented thinking has negative effect on systematic learning. On the other hand, in the micro-age, people have got accustomed to skimming and extensive reading. Traditional reading mode is challenged. When problems appear, we first turn to the network and search engine. Therefore, the network greatly influences our abilities in learning and solving problems. We should think and avoid the baneful influence of fragmented thinking.

\section{F. Micro-culture Requires College Students to Distinguish Information}

Micro-culture can provide convenient and timely as well as good and bad, true and false information difficult for people to distinguish, accompanying by plenty of information garbage and transient information because of lacking strict information verification or review mechanism, just like question bank on the internet. So college students should be able to distinguish effective information.

\section{INFLUENCES OF MICRO-CULTURE ON COLLEGE STUDENTS' CAREER CHOICE BEHAVIOR}

\section{A. Influence of Micro-Culture on Job-Hunting Behavior}

Because of mobilization, universality and convenience of information spreading, micro-culture enables employment information of enterprise easier, making post competition fiercer. At the meantime, it is also an advantageous feature of the new micro-age that people who successfully get the offer from enterprise post interview experience on Weibo, WeChat, website and bbs to help college students in job hunting.

\section{B. Influence of Micro-culture on College Students' Emotions in Job Hunting}

Nowadays, the micro-culture has orientation of nonmainstream value like consumerism, money worship, entertainment, utilitarianism and trust crisis. The physiological characteristics and psychological traits of college students make them changeable, uncertain and unbalanced in society. Because of facing various social pressures very early, college students are eager to success, pursue enjoyment and decency. As a result, they may avoid social responsibility and abandon honesty and morality even their ideals, interests and strong points.

\section{The Influence of Consumption Culture in Micro-culture}

The investigation finds most students are indifferent and incompletely negative to consumerism behavior. It means consumerism is eroding them but not completely. At present, college students hold more rational attitudes toward money and interest, no longer taking the pursuit of them as low moral character. In their opinion, it is reasonable to properly pursue money and interest and consume. However, they expect salaries on the basis of not physical truth but their habits or expectations in consumption ${ }^{[6]}$, so their job expectancy is not practical and high in general, adverse to smooth employment of college students. Moreover, they will have psychological gap in face of real employment, even lose enthusiasm or hold too pessimistic attitude toward employment. People's consuming desires expand continuously and far beyond their real demand under the influence of mass media especially the advertisement, resulting in hedonism.

\section{Influence of Hedonism in Micro-culture}

College students are deeply affected by hedonism, embodying in their view on consumption and life as well as employment. They prefer to light work with comfortable environment, but ideal and reality often run in the opposite 
direction. Therefore, the employment culture construction in school at new period should guide college students to shape employment values and look out the erosion of hedonism on them. Serious influence will be caused on the overall employment environment if college students' employment behavior violates development law ${ }^{[7]}$ of economic society, eroded by hedonism in micro-culture without the correct guidance of social mainstream culture and value.

\section{E. Micro-culture Catalyzes College Students to Start Business}

Micro-culture has expanded college students' thinking space and stimulated their innovation consciousness. Their employment idea is opener and innovative undertaking springs up. In daily consumption, people are no longer conservative and yearn for the past but brave in accepting the newborn college students' innovative undertaking, taking the initiative to propagating for them. Since college students are encouraged by our country to start up business, the pursuit for innovation and change as well as high quality has become value goal in employment selection. Their employment behavior is more standard. High efficiency, justice, equality and mutual benefit have become basic standard of college students' employment behavior.

\section{CONCLUSION}

Micro-culture provides more opportunities for people to get full development of subjectivity. It is more hopeful for life to return to people. Modern people want to be different from the rest through innovation and try. With the most challenging spirit, college students accept new things most easily. In this sense, micro-culture may contain huge value in correcting the development direction of human civilization. ${ }^{[8]}$ It should become the topic of the times, to which the current humanities and social sciences circles and policy-making departments pay attention continuously.

The micro-culture in micro-age has brought great challenges for guidance of college students' learning behavior and career choice behavior as well as historical opportunities, new learning style and employment thinking. College students should find position in new historical trend and adopt good points and avoid shortcomings to become outstanding person in the micro-culture age.

\section{REFERENCES}

[1] Shi Yudong, Xing Qilong. Exploration on Connotation of Micro-culture [J], Journal of Hubei University of Technology, 2013, 03:77-79+88

[2] Wang Minan, Gai Qi, etc. Culture and Art in Micro-age [M], Beijing: China Social Sciences Publishing House, 2015

[3] Zhang Hao, Yang Lingxia, Ding Caoxuan. Analysis on Cultural Background of Burgeoning Micro-learning [J], China Educational Technology, 2014, 02:13-16

[4] Li Long. Discussion on Design and Implementation of "Micro-learning" [J], E-education Research, 2014, 02:74-83

[5] Zhang Hao. Research on Micro-learning Design in New Media Environment [D], Nanjing Normal University, 2012
[6] Yang Lu. Research on College Students' Employment View under Consumption Culture Background [D], Liaoning Normal University, 2014

[7] Wei Pingwei. Discussion on Employment Culture Construction of Young People in the New Age-Guided by Socialist Core Values [J], Journal of China Youth College for Political Sciences, 2013, 04:55-59

[8] Zhao Ting. Research on College Students' Legal Education under Micro-age Background [M], Beijing: Jiuzhou Press, 2014 